\title{
Simulation Model to the Zika Virus Considering Asymptomatic Population
}

\author{
Juan Carlos Jamboos, Dalia Marcela Muñoz, Anibal Muñoz, Oscar Andrés Manrique, \\ Steven Raigosa
}

Grupo de Modelación Matemática en Epidemiología (GMME), Facultad de Educación, Universidad del Quindío, Armenia, Colombia Email: jcjamboos@gmail.com, marcolombia86@hotmail.com

How to cite this paper: Jamboos, J.C., Muñoz, D.M., Muñoz, A., Manrique, O.A. and Raigosa, S. (2018) Simulation Model to the Zika Virus Considering Asymptomatic Population. Open Journal of Modelling and Simulation, 6, 1-12.

https://doi.org/10.4236/ojmsi.2018.61001

Received: March 13, 2017

Accepted: November 21, 2017

Published: November 24, 2017

Copyright $\odot 2018$ by authors and Scientific Research Publishing Inc. This work is licensed under the Creative Commons Attribution International License (CC BY 4.0).

http://creativecommons.org/licenses/by/4.0/

\begin{abstract}
A simulation model based on nonlinear ordinary differential equations to interpret the transmission dynamics of Zika Virus (ZIKV), is formulated and analyzed, integrating the asymptomatic human population and coupled to the Aedes aegypti dynamics, the epidemic threshold Basic Reproduction Number $R_{0}$ is determined, as the spectral radius of Next-Generation Matrix and the system is simulated with MAPLE computing program taking the parameter values from literature.
\end{abstract}

\section{Keywords}

Simulation Models, Zika Virus (ZIKV), Basic Reproductive Number $R_{0}$, Spectral Radius, Asymptomatic, Next-Generation Matrix

\section{Introduction}

The Zika virus (ZIKV) is an arthropod-borne virus belonging to flavivirus family, is transmitted by mosquitoes of the Aedes genus [1]. It was isolated from Aedes africanus in 1948 [2] but its first appearance dates back to 1947, presenting in a monkey from the forests of Zika in Uganda, due to this its name [3]. The first manifestations of this virus in humans occurred in 1952 in East Africa. Between 1977 and 1978 there was an outbreak in Malaysia and Indonesia attributed to a strong rain season. Until 2007 on the Yap Island in Micronesia new cases were detected [4] [5] [6].

ZIKV can be transmitted both sexually and vectorially. Sexually transmitted cases have been reported [1] [7] [8]. Contacting with fluids such as human saliva, blood, semen and urine are among the nonvectorial forms for transmission of the virus [7]. The ZIKV transmission through sexual contact has been suggested 
by Foy et al., who describes two patients infected in the southeast Senegal in 2008 [5].

Until recently, the disease was characterized as clinically mild. The primary symptoms last approximately a week. Around $75 \%$ of infections belong to asymptomatic population [9] [10], there could be a great deal of under reporting of cases since up to $80 \%$ of cases are asymptomatic [11] [12], individuals who are not infectious (asymptomatic period) [13] and rarely there is a need of hospitalization [14]. While the disease can be asymptomatic or cause minor fever and a rash, the virus has also been linked to Guillian-Barré syndrome and microcephaly in infants born to mothers infected during pregnancy [11]. Fever, joint pains, headaches and conjunctivitis are the most relevant symptoms [15].

In ZIKV disease, it's important to consider the asymptomatic people due to the high probability of disseminating the virus among susceptible population in unnoticed way. Some of the studies that have been focused to the ZIKV, such as Fréour et al. (2016), who studied the sexual transmission of this disease, probably among heterosexuals, in a totally asymptomatic couple [16]. Ascertainment bias cannot be ignored for this epidemiological scourge with substantial fraction of asymptomatic and mild infections [17]. A mathematical analysis suggests that ZIKV may exhibit similar dynamics to dengue virus in island populations, with transmission characterized by large, sporadic outbreaks with a high proportion of asymptomatic or unreported cases [18]. Pacheco et al. (2016), presented a study on the general context of ZIKV in Colombia, demonstrating the relationship between the virus and microcephaly. At the same time, he gave a report about asymptomatic people to this illness [19]. When the reproduction number varies between 1.9 and 2.8 based on estimates for Antioquia-Colombia, the attack rate varies between $4 \%$ and $26 \%$ for a low (below 10\%) effectiveness of interventions in blunting the ZIKV transmission from symptomatic cases to mosquitoes [20].

On the other hand, Manrique et al. (2016) presented a mathematical model where the relationship in the transmission of the virus in two ways was explored, both sexual and vectorial, with special emphasis on the consequences of the nonvectorial transmission in the population [21]. Agusto et al. (2017) analyze a new system of ordinary differential equations, which incorporates human vertical transmission of ZIKV, the birth of babies with microcephaly and asymptomatically infected individuals. Their results show that asymptomatic individuals amplify the disease burden in the community and the model was locally and globally asymptotically stable when the $R_{0}$ was less than unity [22]. The same authors [23], set out another model incorporating both vector and sexual transmission routes, finding when there is no disease induced mortality the diseasefree equilibrium is locally and globally asymptotically stable whenever the associated reproduction number is less than unity and unstable otherwise. Padmanabhan et al. (2017), consider two classes of human infectious, asymptomatic and symptomatic, which are assumed to be equally infectious and of similar du- 
ration (period of infectiousness) [24]. Onuorah et al. (2016) suggest a deterministic mathematical model of ZIKV where obtained the $R_{0}$ using the next generation method [25], indicating to be most sensitive to the biting and mortality rate of mosquitoes while sexual transmission increases the risk of infection and epidemic size and prolongs the outbreak [26].

This article suggests and analyzes a simulation model based on nonlinear ordinary differential equations, which interprets the ZIKV transmission, integrating the asymptomatic population and coupled to the A. aegypti dynamics. Subsequently, in its analysis the epidemic threshold basic reproduction number $R_{0}$ by the theory of Next-Generation Matrix, is determined [25]. Finally, simulations of the differential equation system implementing MAPLE software [27] are made.

\section{The Model}

A model for the transmission of the ZIKV with symptomatic and asymptomatic population is formulated (see Figure 1), coupling the carrier and noncarrier adult mosquito population dynamics, considering both infected human populations may transmit ZIKV to the noncarrier mosquitoes. Constant fluxes from susceptible people and from noncarrier mosquitoes, constant rate of human mortality, natural death rate of mosquitoes by environmental conditions and incidence type standard, are assumed. The host-vector infectious process using

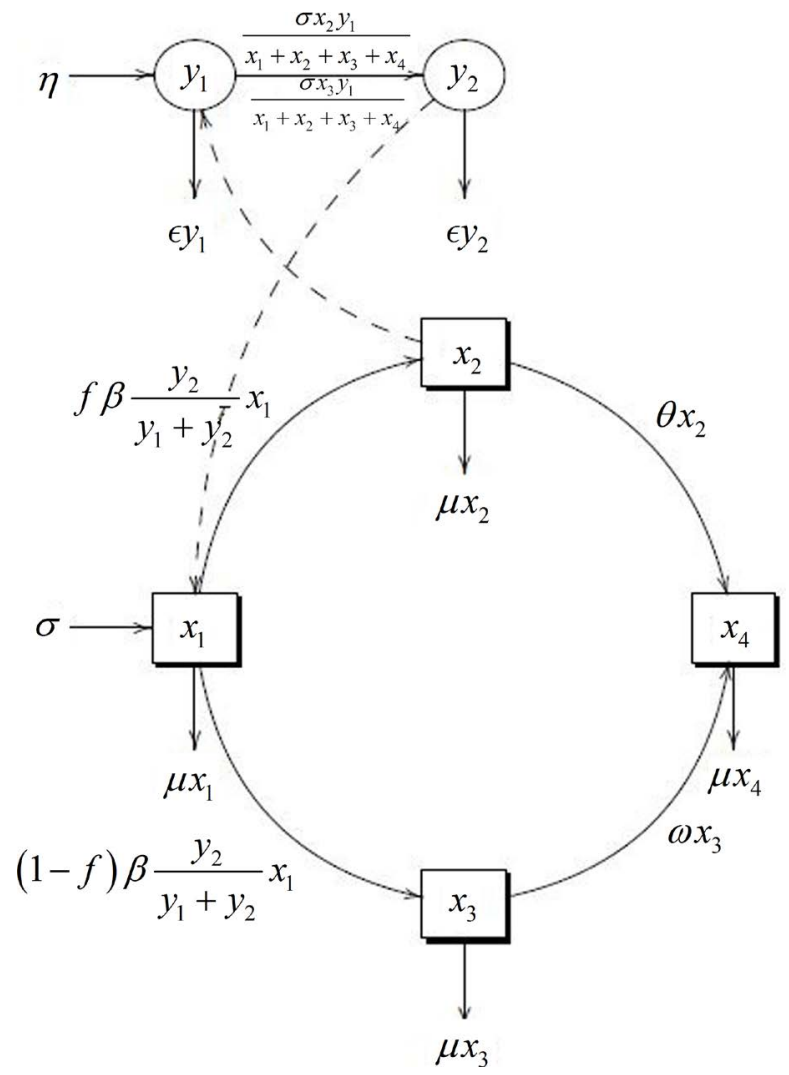

Figure 1. Flow chart of the infectious process. 
nonlinear ordinary differential equations is made, and the epidemic threshold basic reproduction number (i.e. the average number of new cases of infected people during infectious period in the susceptible population) by operated matricial method also known as the Next-Generation Matrix and its respective spectral radius, is determined.

Population variables are time functions, considering $x_{1}(t)=x_{1}, x_{2}(t)=x_{2}$, $x_{3}(t)=x_{3}, \quad x_{4}(t)=x_{4}, \quad y_{1}(t)=y_{1} \quad$ y $\quad y_{2}(t)=y_{2}$.

Variables, initial conditions and parameters of the dynamics are shown in $\mathrm{Ta}$ ble 1 and Table 2. Thus, the dynamic system that interprets the infectious process is as follows:

$$
\begin{gathered}
\frac{\mathrm{d} x_{1}}{\mathrm{~d} t}=\delta-\beta \frac{y_{2}}{\sum_{j=1}^{2} y_{j}} x_{1}-\mu x_{1} \\
\frac{\mathrm{d} x_{2}}{\mathrm{~d} t}=f \beta \frac{y_{2}}{\sum_{j=1}^{2} y_{j}} x_{1}-(\theta+\mu) x_{2} \\
\frac{\mathrm{d} x_{3}}{\mathrm{~d} t}=(1-f) \beta \frac{y_{2}}{\sum_{j=1}^{2} y_{j}} x_{1}-(\omega+\mu) x_{3} \\
\frac{\mathrm{d} x_{4}}{\mathrm{~d} t}=\theta x_{2}+\omega x_{3}-\mu x_{4}
\end{gathered}
$$

Table 1. Variables and initial populations of the model.

\begin{tabular}{ccc}
\hline Variables & Description & Initial populations \\
\hline$x_{1}$ & average of susceptible population & $x_{1}(0)=400.000$ \\
$x_{2}$ & average of asymptomatic population & $x_{2}(0)=10$ \\
$x_{3}$ & average of symptomatic population & $x_{3}(0)=5$ \\
$x_{4}$ & average of recovery population & $x_{4}(0)=0$ \\
$y_{1}$ & average of nontransmitting mosquitoes & $y_{1}(0)=200$ \\
$y_{2}$ & average of transmitting mosquitoes & $y_{2}(0)=10$
\end{tabular}

Table 2. Model of simulation parameters.

\begin{tabular}{ccc}
\hline Parameter & Description & hypothetical value \\
\hline$\delta$ & flow of susceptible population & 30 \\
$\eta$ & nontransmitting mosquitoes growth & 20 \\
$\mu$ & natural mortality rate of population & 0.010 \\
$f$ & asymptomatic population fraction & $0.3,0.7$ \\
$1-f$ & symptomatic population fraction & $0.7,0.3$ \\
$\theta$ & asymptomatic recovery rate & 0.05 \\
$\omega$ & symptomatic recovery rate & 0.3 \\
$\beta$ & transmission probability among persons & 0.7913 \\
$\sigma$ & transmission probability among mosquitoes & 0.773 \\
$\epsilon$ & mortality mosquito rate & 0.035 \\
\hline
\end{tabular}




$$
\begin{gathered}
\frac{\mathrm{d} y_{1}}{\mathrm{~d} t}=\eta-\sigma \frac{y_{1}}{\sum_{i=1}^{4} x_{i}} \sum_{k=2}^{3} x_{k}-\epsilon y_{1} \\
\frac{\mathrm{d} y_{2}}{\mathrm{~d} t}=\sigma \frac{y_{1}}{\sum_{i=1}^{4} x_{i}} \sum_{k=2}^{3} x_{k}-\epsilon y_{2}
\end{gathered}
$$

The equation system (1)-(6) belongs to a dynamic system where each differential equation states the variability of a population in the time. Initial conditions are: $x_{1}(0)=x_{10}, \quad x_{2}(0)=x_{20}, \quad x_{3}(0)=x_{30}, \quad x_{4}(0)=x_{40}, \quad y_{1}(0)=y_{10} \quad$ y $\quad y_{2}(0)=y_{20}$.

We define the epidemiological meaning region, where the solution curves or trajectories of each population are positive, as:

$$
\Omega=\left\{\left(x_{1}, x_{2}, x_{3}, x_{4}, y_{1}, y_{2}\right) \in R_{+}^{6}: 0<\sum_{i=1}^{4} x_{i} \leq \frac{\delta}{\mu}, 0 \leq y_{1}+y_{2} \leq \frac{\eta}{\epsilon}\right\}
$$

\section{Basic Reproduction Number, $\boldsymbol{R}_{0}$}

To calculate the basic reproduction number $R_{0}$, as the spectral radius of the Next-Generation Matrix $\rho(G)$ [28] [29] [30], we rewrite the system (1) to (6), according to the equations of infectious process:

$$
\begin{gathered}
\frac{\mathrm{d} x_{2}}{\mathrm{~d} t}=f \beta \frac{y_{2}}{\sum_{j=1}^{2} y_{j}} x_{1}-(\theta+\mu) x_{2} \\
\frac{\mathrm{d} x_{3}}{\mathrm{~d} t}=(1-f) \beta \frac{y_{2}}{\sum_{j=1}^{2} y_{j}} x_{1}-(\omega+\mu) x_{3} \\
\frac{\mathrm{d} y_{2}}{\mathrm{~d} t}=\sigma \frac{y_{1}}{\sum_{i=1}^{4} x_{i}} \sum_{k=2}^{3} x_{k}-\epsilon y_{2} \\
\frac{\mathrm{d} x_{1}}{\mathrm{~d} t}=\delta-\beta \frac{y_{2}}{\sum_{j=1}^{2} y_{j}} x_{1}-\mu x_{1} \\
\frac{\mathrm{d} x_{4}}{\mathrm{~d} t}=\theta x_{2}+\omega x_{3}-\mu x_{4} \\
\frac{\mathrm{d} y_{1}}{\mathrm{~d} t}=\eta-\sigma \frac{y_{1}}{\sum_{i=1}^{4} x_{i}} \sum_{k=2}^{3} x_{k}-\epsilon y_{1}
\end{gathered}
$$

This system has the $\dot{X}=\Gamma(X)-\Phi(X)$ form, where,

$$
\Gamma(X)=\left(\begin{array}{c}
f \beta \frac{y_{2}}{\sum_{j=1}^{2} y_{j}} x_{1} \\
(1-f) \beta \frac{y_{2}}{\sum_{j=1}^{2} y_{j}} x_{1} \\
\sigma \frac{\sum_{k=2}^{3} x_{k}}{\sum_{i=1}^{4} x_{i}} y_{1} \\
0 \\
0 \\
0
\end{array}\right) \text { y }(X)=\left(\begin{array}{c}
(\theta+\mu) x_{2} \\
(\omega+\mu) x_{3} \\
\epsilon y_{2} \\
-\delta+\beta \frac{y_{2}}{\sum_{j=1}^{2} y_{j}} x_{1}+\mu x_{1} \\
-\theta x_{2}-\omega x_{3}+\mu x_{4} \\
-\eta+\sigma \frac{\sum_{k=2}^{3} x_{k}}{\sum_{i=1}^{4} x_{i}} y_{1}+\epsilon y_{1}
\end{array}\right)
$$


With $F$ in the equilibrium point $E_{0}=\left(\frac{\delta}{\mu}, 0,0,0, \frac{\eta}{\epsilon}, 0\right)$,

$$
\begin{aligned}
& F=\left(\frac{\partial \Gamma(X)}{\partial X}\right)\left(E_{0}\right)=\left(\begin{array}{ccc}
0 & 0 & \frac{f \beta \hat{x}_{1} \hat{y}_{1}}{\left(\sum_{j=1}^{2} y_{j}\right)^{2}} \\
0 & 0 & \frac{(1-f) \beta \hat{x}_{1} \hat{y}_{1}}{\left(\sum_{j=1}^{2} y_{j}\right)^{2}} \\
\frac{\sigma \hat{y}_{1}\left(\hat{x}_{1}+\hat{x}_{2}\right)}{\left(\sum_{i=1}^{4} x_{i}\right)^{2}} & \frac{\sigma \hat{y}_{1}\left(\hat{x}_{1}+\hat{x}_{2}\right)}{\left(\sum_{i=1}^{4} x_{i}\right)^{2}} & 0
\end{array}\right) \\
& =\left(\begin{array}{ccc}
0 & 0 & \frac{f \beta \hat{x}_{1}}{\hat{y}_{1}} \\
0 & 0 & \frac{p \hat{x}_{1}}{\hat{y}_{1}} \\
\frac{\sigma \hat{y}_{1}}{\hat{x}_{1}} & \frac{\sigma \hat{y}_{1}}{\hat{x}_{1}} & 0
\end{array}\right)=\left(\begin{array}{ccc}
0 & 0 & \frac{f \beta \delta \epsilon}{\mu \eta} \\
0 & 0 & \frac{p \beta \delta \epsilon}{\mu \eta \epsilon} \\
\frac{\sigma \eta \mu}{\delta \epsilon} & \frac{\sigma \eta \mu}{\delta \epsilon} & 0
\end{array}\right) \\
& V=\left(\frac{\partial \Phi(X)}{\partial X}\right)\left(E_{0}\right)=\left(\begin{array}{ccc}
\theta+\mu & 0 & 0 \\
0 & \omega+\mu & 0 \\
0 & 0 & \epsilon
\end{array}\right)
\end{aligned}
$$

and its inverse,

$$
V^{-1}=\left(\begin{array}{ccc}
\frac{1}{\theta+\mu} & 0 & 0 \\
0 & \frac{1}{\omega+\mu} & 0 \\
0 & 0 & \frac{1}{\epsilon}
\end{array}\right)
$$

i.e., the Next-Generation Matrix is,

$$
G=F \cdot V^{-1}=\left(\begin{array}{ccc}
0 & 0 & \frac{f \beta \delta \epsilon}{\mu \eta \epsilon} \\
0 & 0 & \frac{(1-f) \beta \delta \epsilon}{\mu \eta \epsilon} \\
\frac{\sigma \eta \mu}{\delta \epsilon(\theta+\mu)} & \frac{\sigma \eta \mu}{\delta \epsilon(\omega+\mu)} & 0
\end{array}\right)
$$

and its corresponding characteristic equation $|G-\lambda I|=0$, is

$$
\lambda\left[\lambda^{2}-\frac{f \beta \sigma}{(\theta+\mu) \epsilon}-\frac{(1-f) \beta \sigma}{(\omega+\mu) \epsilon}\right]=0
$$

which has the following eigen values, $\lambda_{1}=0$ and

$$
\lambda_{1,2}= \pm \sqrt{\frac{f \beta \sigma}{(\theta+\mu) \epsilon}+\frac{(1-f) \beta \sigma}{(\omega+\mu) \epsilon}}
$$


Therefore, the spectral radius of $G$ is,

$$
\rho(G)=\max \left\{0, \pm \sqrt{\frac{f \beta \sigma}{(\theta+\mu) \epsilon}+\frac{(1-f) \beta \sigma}{(\omega+\mu) \epsilon}}\right\}
$$

and the threshold, basic reproductive number,

$$
R_{0}(f)=\sqrt{\frac{f \beta \sigma}{(\theta+\mu) \epsilon}+\frac{(1-f) \beta \sigma}{(\omega+\mu) \epsilon}}
$$

i.e., $R_{0}(f)=\sqrt{R_{0}^{a}(f)+R_{0}^{s}(f)}$, where

$$
R_{0}^{a}(f)=\frac{f \beta \sigma}{(\theta+\mu) \epsilon}, R_{0}^{s}(f)=\frac{(1-f) \beta \sigma}{(\omega+\mu) \epsilon}
$$

where $R_{0}^{a}(f)$ and $R_{0}^{s}(f)$ is the number of secondary cases for asymptomatic infected people and the number of secondary cases for symptomatic infected people respectively, as function of the asymptomatic population fraction.

\section{Simulation of the Model}

Figure 2, shows the graphics of the lineal epidemic thresholds in $f$ for asymptomatic and symptomatic population and the basic reproduction number $R_{0}$, dependent on the asymptomatic population fraction. The system is simulated with Maple software for a $30 \%$ and $70 \%$ of asymptomatic population.

According to Figure 3, for $30 \%$ of asymptomatic population, itself reaches its maximum in 81000 individuals about 10 days later (black line), stabilizing at 90 days, while the population of symptomatic reaches a maximum value in 98000

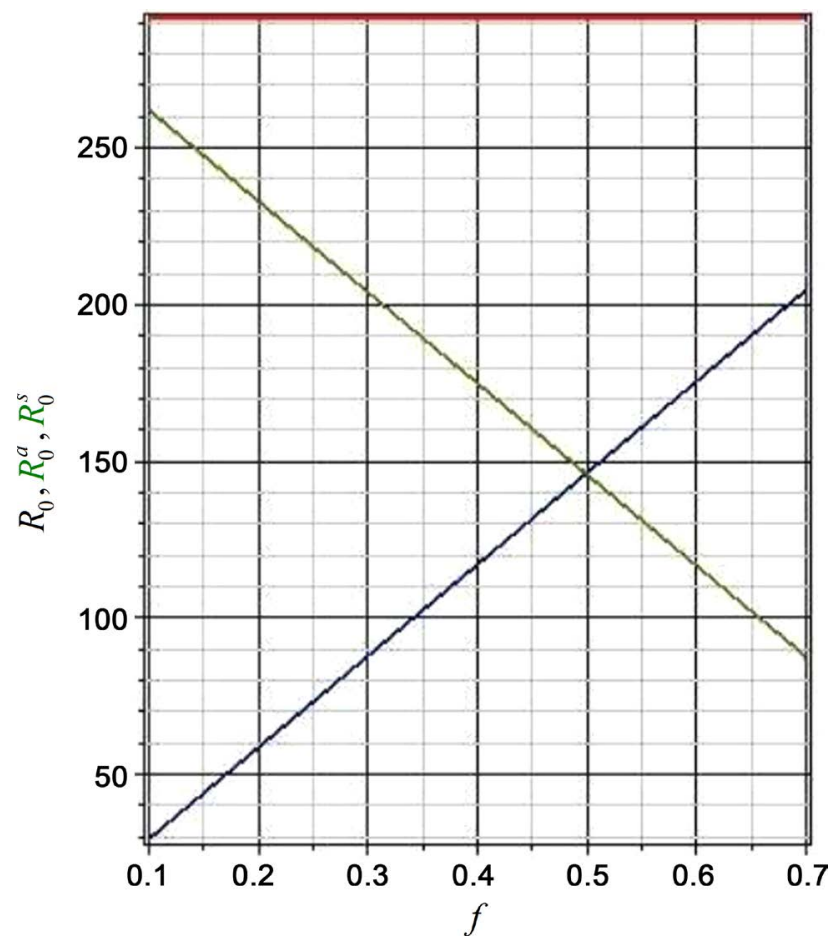

Figure 2. Behaviour of the thresholds $R_{0}(f), R_{0}^{a}(f)$ and $R_{0}^{s}(f)$. 


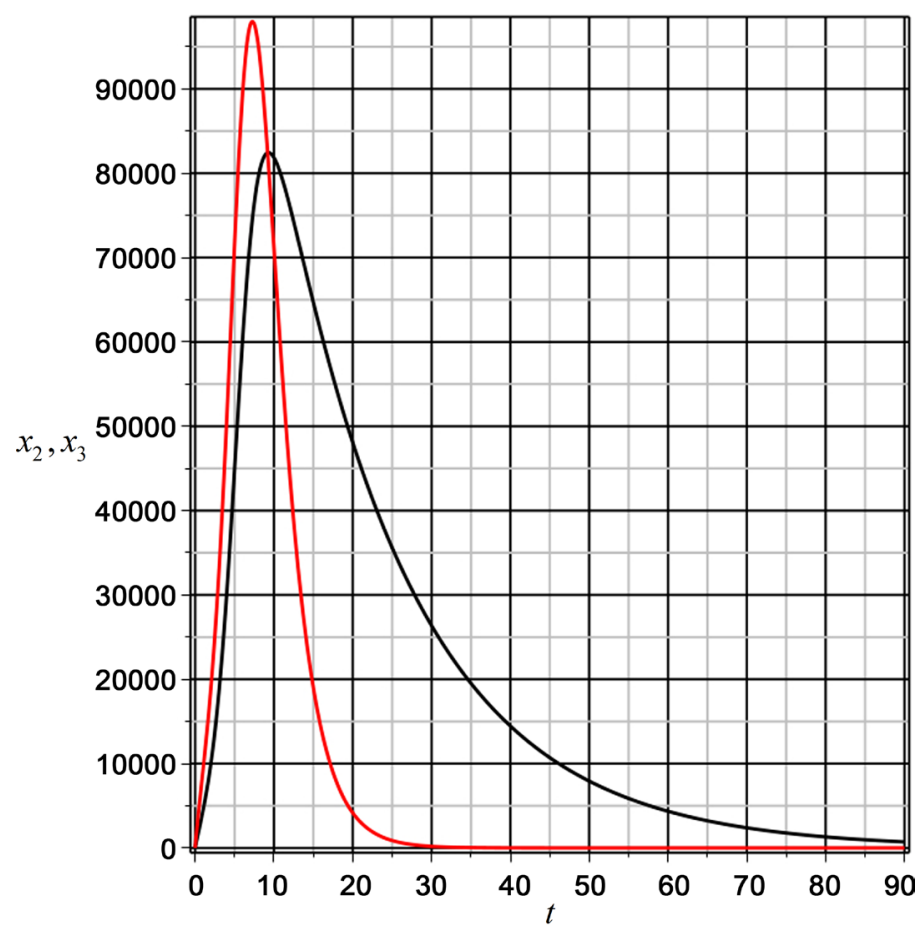

(a)

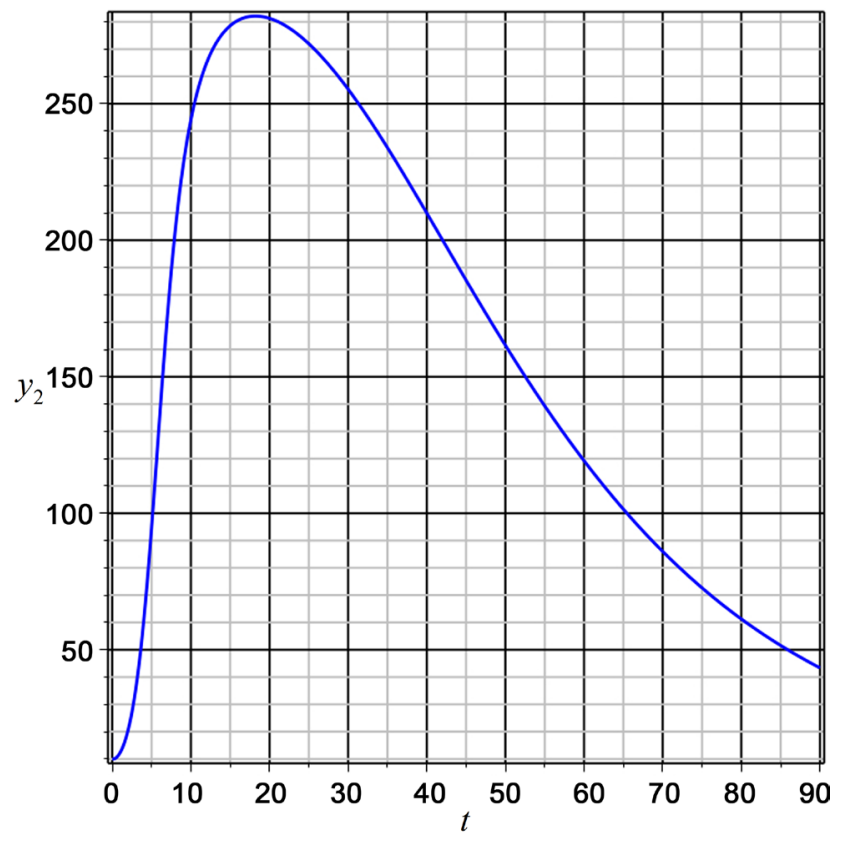

(b)

Figure 3. Asymptomatic and symptomatic populations and transmitting mosquitoes population with $f=30 \%$.

individuals in 7 days (red line), increasing and decreasing fast to stabilize without infection in 30 days. In addition, it shows the behavior of the population of transmitting mosquitoes, for a $30 \%$ of asymptomatic population. The population grows up fast to a maximum value of 290 transmitting mosquitoes to 180 days slowly decreasing to zero in more than 100 days (blue line). 
Figure 4, shows a population with a very fast growth of the asymptomatic population up to a maximum value of 195000 individuals in 10 days (black line), decreasing to stabilize in a low level after 90 days, while the symptomatic population stabilizes without infection around the 30 days (red line). For $70 \%$ of asymptomatic human population, the transmitting mosquitoes increase fast up

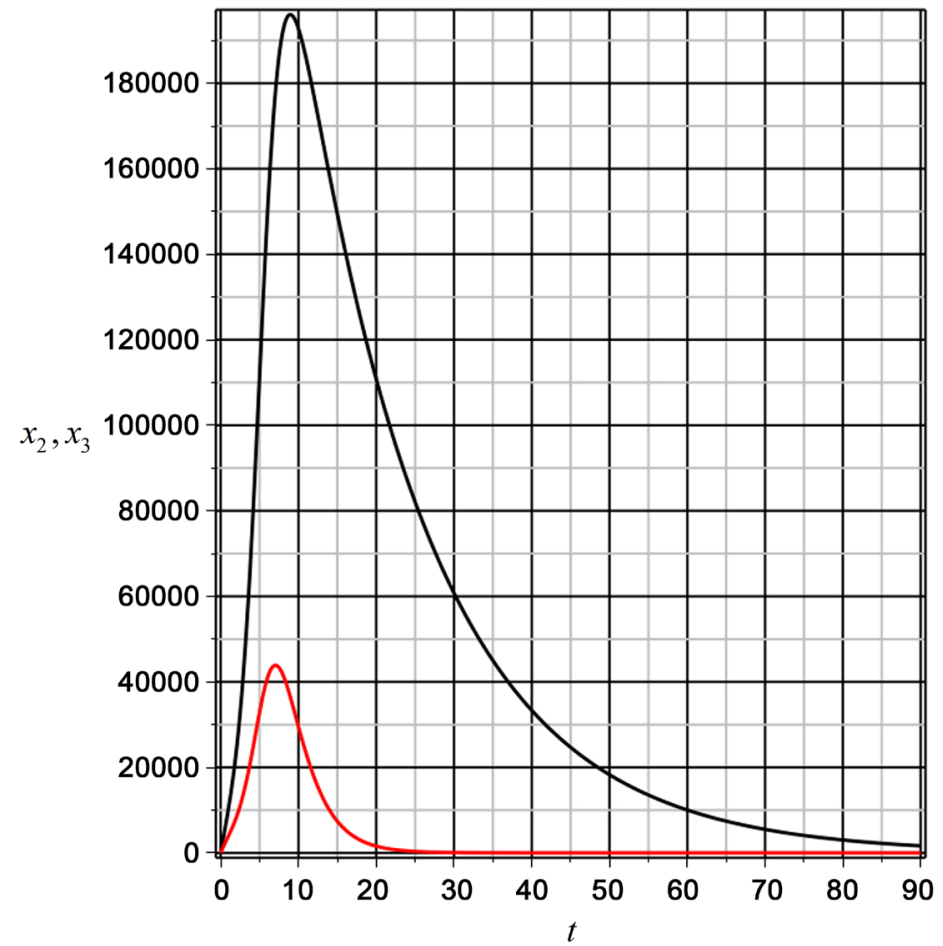

(a)

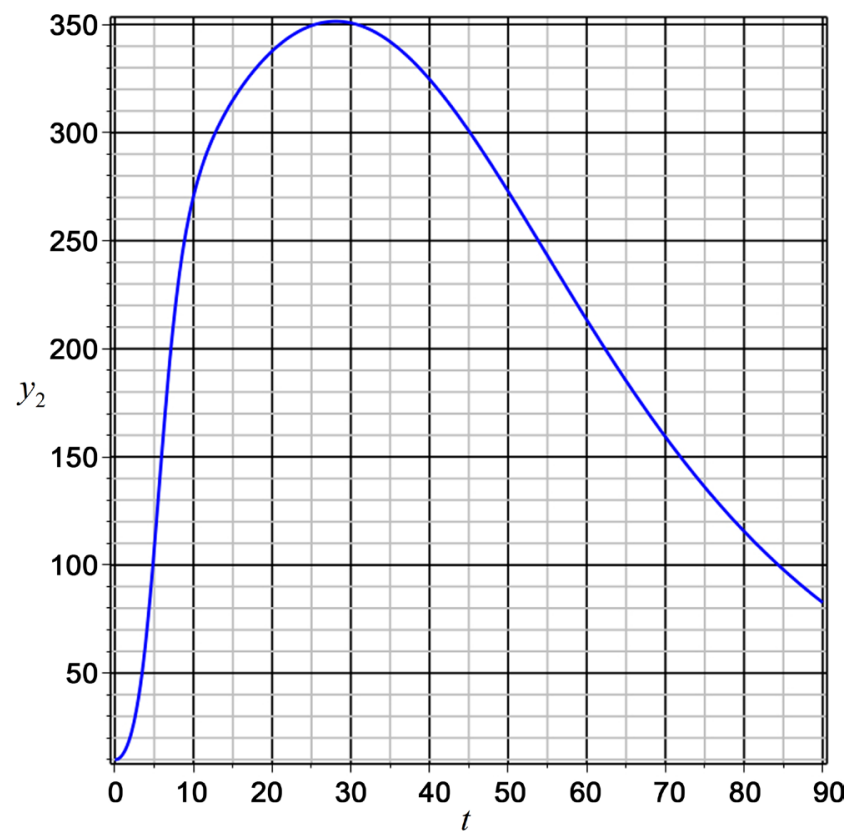

(b)

Figure 4. Asymptomatic and symptomatic populations and transmitting mosquitoes population with $f=70 \%$. 
to reach its maximum at 350 transmitting mosquitoes around 28 days later (blue line) and from this value slowly decreases.

\section{Result and Conclusions}

To determine $R_{0}$, the infectious stages are considered, i.e. $x_{3}, x_{7}, x_{2}, x_{6}$ y $y_{2}$. Following the approach of the Next-Generation Matrix [28] [29] [30], we obtain the basic reproduction number, given by:

$$
R_{0}=\sqrt{\frac{\sigma \beta_{1} f}{\epsilon\left(\alpha_{1}+\mu\right)}+\frac{\beta_{2} \sigma(1-(f+g+h))}{\epsilon\left(\alpha_{2}+\mu\right)}}
$$

To understand better the meaning of the basic reproduction number, the additive and multiplicative effects of $R_{0}$ indicate that vector can transmit the DENV or CHIKV to the susceptible population. The terms $\frac{\beta_{1} f}{\epsilon}$ and $\frac{\beta_{2}(1-(f+g+h))}{\epsilon}$ indicate the incidence of new cases of DENV or CHIKV in the susceptible population respectively, during the lifetime of vector. The expression $\frac{\sigma}{\alpha_{1}+\mu}$ corresponds to the DENV incidence in nontransmitting mosquitoes. On the other hand, the expression $\frac{\sigma}{\alpha_{2}+\mu}$ represents the CHIKV incidence in nontransmitting mosquitoes.

\section{Acknowledgements}

Thanks Grupo de Modelación Matemática en Epidemiología (GMME), Facultad de Educación, Universidad del Quindío-Colombia.

\section{References}

[1] Gatherer, D. and Kohl, A. (2016) Zika Virus: A Previous Slow Pandemic Spreads Rapidly through the Americas. Journal of General Virology, Article ID: 26684466. https://doi.org/10.1099/jgv.0.000381

[2] Caminade, C., Turner, J., Metelmann, S., Hesson J.C., Blagrove, M.S., Solomon, T., Morse, A.P. and Baylis, M. (2017) Global Risk Model for Vector-Borne Transmission of Zika Virus Reveals the Role of El Niño 2015. PNAS, 114, 119-124. https://doi.org/10.1073/pnas.1614303114

[3] Patiño, A.M., Medina. I., Gil-Restrepo. A.F. and Rodríguez-Morales, A.J. (2015) Zika: otra infección de transmisión sexual [Zika: another sexually transmitted infection]. Sexually Transmitted Infections, 91, 359. https://doi.org/10.1136/sextrans-2015-052189

[4] Musso, D., Roche, C., Nhan, T.X., Robin, E., Teissier, A. and Cao-Lormeau, V.M. (2015) Detección del virus Zika en la saliva [Detection of Zika Virus in Saliva]. Journal of Clinical Virology, 68, 53-55. https://doi.org/10.1016/j.jcv.2015.04.021

[5] Foy, B.D., Kobylinski, K.C., Chilson-Foy, J.L., Blitvich, B.J., Travassos da Rosa, A., Haddow, A.D., Lanciotti, R.S. and Tesh, R.B. (2011) Probable transmisin no transmitidas por vectores del virus Zika, Colorado, EE.UU [Probable Non-Vector-Borne Transmission of Zika Virus, Colorado, USA]. Emerging 
Infections Diseases, 17, 880-882. https://doi.org/10.3201/eid1705.101939

[6] Rodríguez, A.J. (2015) Zika: The New Arbovirus Threat for Latin America. Journal of Infection in Developing Countries, 9, 684-685. https://doi.org/10.3855/jidc.7230

[7] Duffy, M.R., Chen, T.H, Hancock, W.T., Powers, A.M., Kool, J.L., Lanciotti, R.S., Pretrick, M., Marfel, M., Holzbauer, S., Dubray, C., Guillaumot, L., Griggs, A., Bel, M., Lambert, A.J., Laven, J., Kosoy, O., Panella, A., Biggerstaff, B.J., Fischer, M. and Hayes, E.B. (2009) Zika Outbreak on Yap Island, Federated States of Micronesia. The New England Journal Medicine, 366, 2536-2543. https://doi.org/10.1056/NEJMoa0805715

[8] Wong, P.S., Li, M.Z., Chong, C.S., Ng, L.C. and Tan, C.H. (2013) Aedes (Stegomyia) albopictus (Skuse): A Potential Vector of Zika Virus in Singapore. PLOS Neglected Tropical Diseases, 8, e2348. https://doi.org/10.1371/journal.pntd.0002348

[9] OMS (2015) Infección por el virus de Zika-Brasil y Colombia [Infection by Zika Virus-Brasil and Colombia]. http://www.who.int/csr/don/21-october-\%202015-zika/es/

[10] Gourinat, A.C., O’Connor, O., Calvez, E., Goarant, C. and Dupont-Rouzeyrol, M. (2015) La detección de virus Zika en la orina. [Detection of Zika Virus in Urine.] Emerging Infectious Diseases, 21, 84-86.

[11] Oleson, C. and Artzrouni, M. (2016) A Patch Model for the Transmission Dynamiss of Zika Virus from Rio de Janeiro to Miami during Carvival and the Olympics. https://www.siam.org/students/siuro/vol9/S01542.pdf

[12] Manore, C., Ostfeld, R.S., Agusto, F.B., Gaff, H. and LaDeau, S.H. (2017) Defining the Risk of Zika and Chikunguya Virus Transmission in Human Population Centers of the Eastern United States. PLOS Neglected Tropical Diseases, 11, e0005255. https://doi.org/10.1371/journal.pntd.0005255

[13] Dantas, E., Tosin, M., Peterson, J., Lopes, V. and Cunha, A.Jr. (2016) A Mathematical Analysis abour Zika Virus Outbreak in Rio de Janeiro. 4th Conference of Computational Interdisciplinary Science, São José dos Campos, Brazil.

[14] Rey, J.R., Lounibos, L.P., Alto, B.W., Burkett-Cadena, N.D., Lord, C.C., Smartt, C.T. and Connelly, C.R. (2016) El Zika, un Virus transmitido por mosquitos [Zika, a Mosquito-Borne Virus]. Departamento de Entomología y Nematología. Servicio de Extensión Cooperativa de la Florida. Instituto de Alimentos y Ciencias Agricolas, Universidad de la Florida (UF/IFAS).

[15] Olivera, D., Kelly, V., Prieto, J., Ardila, C. and Cordovez, J.M. (2016) Sexual Transmission's Role on the Zika's Virus Spread. https://mcmsc.asu.edu/sites/default/files/olivera2016.pdf

[16] Frour, T., Miralli, S., Hubert, B., Splingart, C., Barrire, P., Maquart, M., and Leparc-Goffart, I. (2016) Sexual Transmission of Zika Virus in an Entirely Asymptomatic Couple Returning from a Zika Epidemic Area, France, April 2016. Euro Surveill, 21, pii=30254.

[17] Nah, K., Mizumoto, K., Miyamatsu, Y., Yasuda, Y., Kinoshita, R. and Nishiura, H. (2016) Estimating Risks of Importation and Local Transmission of Zika Virus Infection. PeerJ, 4, e1904. https://doi.org/10.7717/peerj.1904

[18] Kucharski, A.J., Funk, S., Eggo, R.M., Mallet, H.P., Edmunds, W.J. and Nilles, E.J. (2016) Transmission Dynamics of Zika Virus in Island Populations: A Modelling Analysis of the 2013-14 French Polynesia Outbreak. PLOS Neglected Tropical Diseases, 10, e0004726. https://doi.org/10.1371/journal.pntd.0004726 
[19] Pacheco, O., Beltrán, M., Nelson, C.A., Valencia, D., Tolosa, N., Farr, S.L., Pardo, L., Padilla, A.V., Tong, V.T., Cuevas, E.L., Espinosa-Bode, A., Rico, A., Reefhuis, J., González, M., Mercado, M., Chaparro, P., Martínez Duran, M., Rao, C.Y., Muñoz, M.M., Powers, A.M., Cuéllar, C., Helfand, R., Huguett, C., Jamieson, D.J., Honein, M.A. and Ospina Martínez, M.L. (2016) ISO 690. ISO, Geneva.

[20] Moghadas, S.M., Shoukat, A., Espindola, A.L., Pereira, R., Abdirizak, F., Laskowski, M., Viboud, C. and Chowell, G. (2017) Asymptomatic Transmission and the Dynamics of Zika Infection. Scientific Reports, 7, Article No. 5829. https://doi.org/10.1038/s41598-017-05013-9

[21] Manrique, O.A., Muñoz, D.M., Muñoz, A., García, J.A., Muñoz, C.A., Osorio, S.R. and Montoya, J.F. (2016) A Simulation Model for Sexual and Vectorial Transmission of Zika Virus (ZIKV). Open Journal of Modelling and Simulation, 5, 70. https://doi.org/10.4236/ojmsi.2017.51006

[22] Agusto, F.B., Bewick, S. and Fagan, W.F. (2017) Mathematical Model of Zika Virus with Vertical Transmission. Infectious Disease Modelling, 2, 244-267.

[23] Agusto, F.B., Bewick, S. and Fagan, W.F. (2017) Mathematical Model of Zika Virus Dynamics with Sexual Transmission Route. Ecological Complexity, 29, 61-81.

[24] Padmanabhan, P., Seshaiyer, P. and Castillo-Chavez, C. (2017) Mathematical Modelling, Analysis and Simulation of the Spread of Zika with Influence of Sexual Transmission and Preventive Measures. Letters in Biomathematics, 4, 148-166. https://doi.org/10.1080/23737867.2017.1319746

[25] Onuorah, M., Ademu, A., Obi, E. and Hasheem, A. (2016) Deterministic Mathematical Model of Zika Virus. Research Journal of Mathematics, 3.

[26] Gao, D., Lou, Y., He, D., Porco, T.C., Kuang, Y., Chowell, G. and Ruan, S. (2016) Prevention and Control of Zika as a Mosquito-Borne and Sexually Transmitted Disease: A Mathematical Modeling Analysis. Scientific Reports, 6, Article No. 28070. https://doi.org/10.1038/srep28070

[27] Oluyo, T.O. and Adeyemi, M.O. (2016) Mathematical Analysis of Zika Epidemic Model. IOSR Journal of Mathematics, 12, 21-33.

[28] Diekmann, O., Heesterbeek, J. and Roberts, M. (2010) The Construction of Next-Generation Matrices for Compartmental Epidemic Models. Journal of the Royal Society Interface, 7, 873-885. https://doi.org/10.1098/rsif.2009.0386

[29] Van, P. and Watmough, J. (2002) Reproduction Numbers and Sub-Threshold Endemi Equilibria for Compartmental Models of Disease Transmission. Elsevier Mathematical Biosciences, 180, 29-48.

[30] Holland, J. (2007) Notes on $R_{0}$. https://web.stanford.edu/ jhj1/teachingdocs/Jones-on-R0.pdf 